\title{
Review \\ Long-Term Use of Proton Pump Inhibitors in Cancer Patients: An Opinion Paper
}

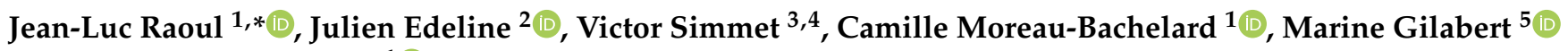 \\ and Jean-Sébastien Frénel ${ }^{1}$ (I)
}

1 Department of Medical Oncology, Institut de Cancérologie de l'Ouest, 44805 Saint-Herblain, France; camille.moreau-bachelard@ico.unicancer.fr (C.M.-B.); jean-sebastien.frenel@ico.unicancer.fr (J.-S.F.)

2 Department of Medical Oncology, Centre E Marquis, 35000 Rennes, France; j.edeline@rennes.unicancer.fr

3 Department of Medical Oncology, Institut de Cancérologie de l'Ouest, 49055 Angers, France; victor.simmet@ico.unicancer.fr

4 Department of Medical Oncology, Centre Hospitalier de Cholet, 49300 Cholet, France

5 Department of Medical Oncology, Centre Hospitalier Universitaire Vaudois, 1011 Lausanne, Switzerland; marine.gilabert@chuv.ch

* Correspondence: jean-luc.raoul@ico.unicancer.fr

Citation: Raoul, J.-L.; Edeline, J.; Simmet, V.; Moreau-Bachelard, C.; Gilabert, M.; Frénel, J.-S. Long-Term Use of Proton Pump Inhibitors in Cancer Patients: An Opinion Paper. Cancers 2022, 14, 1156. https:// doi.org/10.3390/cancers14051156

Academic Editor: Isabelle Van Seuningen

Received: 23 January 2022

Accepted: 18 February 2022

Published: 24 February 2022

Publisher's Note: MDPI stays neutral with regard to jurisdictional claims in published maps and institutional affiliations.

Copyright: (C) 2022 by the authors. Licensee MDPI, Basel, Switzerland. This article is an open access article distributed under the terms and conditions of the Creative Commons Attribution (CC BY) license (https:// creativecommons.org/licenses/by/ $4.0 /)$.
Simple Summary: Proton pump inhibitors are frequently used in cancer patients to alleviate some symptoms, epigastric pain or heartburn. However, acid suppression decreases the absorption of some oral-targeted anticancer treatments (tyrosine kinase inhibitors, CDK4/6 inhibitors) and induces changes in the gut microbiome. Recent data are showing that these interactions have important clinical impacts and medical oncologists and patients must be aware of these possible interactions.

\begin{abstract}
Multikinase inhibitors (MKIs), and particularly tyrosine kinase inhibitors (TKIs) and immune checkpoint inhibitors (CPIs), are currently some of the major breakthroughs in cancer treatment. Proton pump inhibitors (PPIs) revolutionised the treatment of acid-related diseases, but are frequently overused for epigastric pain or heartburn. However, long-term acid suppression from using PPIs may lead to safety concerns, and could have a greater impact in cancer patients undergoing therapy, like bone fractures, renal toxicities, enteric infections, and micronutrient deficiencies (iron and magnesium). Moreover, acid suppression may also affect the pharmacokinetics of drugs (at least during acid suppression) and decrease the absorption of many molecularly-targeted anticancer therapies, which are mostly weak bases with $\mathrm{pH}$-dependent absorption. This type of drug-drug interaction may have detrimental effects on efficacy, with major clinical impacts described for some orally administrated targeted therapies (erlotinib, gefitinib, pazopanib, palbociclib), and conflicting results with many others, including capecitabine. Furthermore, the long-term use of PPIs results in severe alterations to the gut microbiome and recent retrospective analyses have shown that the benefit of using CPIs was suppressed in patients treated with PPIs. These very expensive drugs are of great importance because of their efficacy. As the use of PPIs is not essential, we must apply the precautionary principle. All these data should encourage medical oncologists to refrain from prescribing PPIs, explaining to patients the risks of interaction in order to prevent inappropriate prescription by another physician.
\end{abstract}

Keywords: proton pump inhibitors; cancer; tyrosine kinase inhibitors checkpoint inhibitors; drug interactions; efficacy

\section{Introduction}

Proton pump inhibitors (PPIs) are one of the most frequently prescribed drugs in the world, and are ranked in the top 10 of US national health-related drug expenditures [1]. These highly efficient drugs in "acid related diseases" are widely available, including "over-the-counter" and at low cost, and are frequently prescribed inappropriately outside 
of their proven indications (gastric and duodenal ulcer, reflux oesophagitis, prevention of gastrointestinal bleeding when combined with non-steroidal anti-inflammatory drugs, Zollinger-Ellison syndrome) and in long-term use. This overuse is estimated between $40 \%$ to $80 \%$ in different countries [2,3]. Fortunately, they are very well tolerated, but the initial phase of omeprazole development was stopped when it was shown that carcinoids (ECLome) developed in the oxyntic mucosa in rodents [4]. Nevertheless, in the last decade, growing concerns have emerged regarding their safety, with a large number of studies reporting long-term toxicity, including cancer (of gastric, pancreatic, liver and biliary tract location) [5]. Cancer patients are fragile and many receive long-term PPIs. In a prospective study in four French Comprehensive Cancer Centres, we show that more than a quarter of cancer patients used PPIs, mostly on a daily basis and in the long term [6].

Certain side effects of long-term PPI use may be of greater impact in cancer patients than in the general population. On the other hand, long-term suppression of gastric acidity can decrease the absorption, and thus the efficacy, of certain major oral anticancer drugs, as well as changing the composition of the gut microbiome, which also has an impact on the response to immunotherapy [7]. This means that a symptomatic treatment that is not mandatory but is easily removable, might not only produce side effects, but also worsens patients' prognosis [8,9]. The use of PPIs in cancer patients is thus a real issue [10].

In this review, we aim to update these potential interactions between long-term use of PPIs and cancer patients and their treatment, as well as to propose some possible solutions for cancer patients suffering from heartburn.

\section{Systemic Toxicity Linked to Long-Term PPI Use with a Possible Impact in Cancer Patients}

\subsection{Dementia}

This question is of particular importance as the use of PPI therapy peaks in older people and cancer predominantly affects the elderly. The biological rationale is based on vitamin B12 deficiency, interaction with certain brain enzymes, and enhanced brain betaamyloid levels (decreased degradation by lysosomes) [1,11]. A large German prospective cohort study, using observational data, followed more than 73,000 participants over the age of 75 years and free of dementia at baseline. Patients regularly using PPIs $(n=2950)$ had a significant risk of incident dementia compared with those not using PPIs (HR = 1.44; 95\%CI: 1.36-1.52) [12]. Four retrospective and prospective cohorts, however, did not confirm this association [5], which is considered weak [1] when using the Hill criteria (association or causation) [13].

\subsection{Bone Fractures}

It is now widely accepted that PPI use is a risk factor for the development of osteoporosis and osteoporotic fractures [14-16]. This can be due to malabsorption of calcium, secondary hyperparathyroidism, and vitamin B12 deficiency. This side effect can be of major importance in the cancer patient population which has accelerated bone loss because of their cancer management [17].

\subsection{Renal Toxicities}

In a population-based cohort, PPI use was associated with a 20-50\% higher risk of incident chronic kidney disease, as well as of acute kidney injury [18]. Recently, it has been shown that in patients with chronic kidney disease, chronic use of PPIs accelerates progression of the kidney disease and increases mortality [19]. Another recent retrospective observational study confirmed that in adults with chronic kidney disease, the use of PPIs was associated with an increased risk of hospitalization and mortality [20]. Taking into account the nephrotoxicity (acute but also chronic) of many anticancer drugs, associating them with PPIs should certainly be avoided. 


\subsection{Enteric Infections}

The use of PPIs reduces gastric acidity, leading to changes in the gut microbiome, in the same way that antibiotics do. It also decreases colonization resistance to esophageal candidosis and enteric infections including Clostridium difficile, Campylobacter and Salmonella [7]. On a population level, the effect of PPIs on the gut microbiome is more prominent than the effects of antibiotics [21]. These PPI-induced changes in the microbiome may have a clinical impact, particularly in terms of the development of Clostridium difficile infections in the general population. The use of PPIs is also associated with an increased risk of community-acquired pneumonia [22]. In the frail population of cancer patients, long-term PPI prescription may lead to a high risk of enteric infections.

\subsection{Micronutrient Deficiencies}

Gastrointestinal acidity is important for the absorption of minerals (iron, calcium, magnesium) and vitamin B12. Patients with gastrinoma needing long-term use of high doses of PPIs are a natural model for studying their long-term effects in humans [23]. In this population, long-term use of PPIs was not associated with a decrease in total body stores or iron deficiency [24]. However, in a randomised controlled study in patients with hereditary haemochromatosis, long-term administration of PPIs significantly reduced the volume of blood needed to be removed annually to maintain serum ferritin at $50 \mu \mathrm{g} / \mathrm{L}$, and 7 days of PPIs significantly decreased absorption of non-haem iron from meat [25,26]. Nevertheless, the development of iron deficit anaemia in patients on long-term PPIs seems infrequent and it is always necessary to exclude other causes. Anaemia in cancer patients often has multiple causes; however, avoiding unnecessary PPIs could be a good policy.

Hypomagnesaemia (decreased absorption and increased renal leaks) due to PPIs has been well documented and many dramatic cases have been reported [27]. In 2011, the US FDA released a warning about low serum magnesium levels associated with long-term PPI use. A cross-sectional study in hospitalised patients in Buenos Aires demonstrated that $36 \%$ of patients with chronic PPI use had hypomagnesaemia on admission [28]. Association with other drugs used in oncology, and sometimes themselves, the cause of severe hypomagnesaemia, such as cisplatin and EGF receptor antagonists (monoclonal antibodies and tyrosine kinase inhibitors), requires regular follow-up of magnesaemia.

\section{PPIs and Oncologic Treatment Efficacy}

The concomitant use of oral antineoplastic agents in patients who are long-term PPI users is a real concern because of the consequences of severe chronic acid suppression, as well as the modifications to the intestinal microbiome.

Many papers have addressed the question of the effects of acid suppressive compounds (PPIs and $\mathrm{H} 2$ antagonists) on the bioavailability of oral anticancer agents. As TKIs are weakly basic, when the gastric $\mathrm{pH}$ is elevated (through the use of PPIs or H2 antagonists) the solubility and bioavailability of these drugs may decrease significantly [29,30]. This decreased bioavailability can sometimes be significant and associated with decreased efficacy. One review reported a major decrease in the oral absorption of crizotinib, dasatinib, erlotinib, gefitinib, lapatinib and pazopanib, and recommended avoiding concomitant use of PPIs or $\mathrm{H} 2$ antagonists [31]. A recent systematic review and meta-analysis of the use of gastric-acid suppressants and oral anticancer treatments supports the evidence of a possible negative impact of such combinations on survival outcomes [32].

In parallel, there is increasing evidence suggesting that the gut microbiome can modulate the host's antitumor response and the response to immune checkpoint inhibitors. It has been shown that antibiotics can inhibit the clinical benefits of immune checkpoint inhibitors by modifying the composition of the gut microbiome [33]. PPIs decrease bacterial richness and induce changes in the gut microbiome; these effects are more prominent than the effects of antibiotics [21]. 


\subsection{PPIs and Tyrosine Kinase Inhibitors (TKIs)}

TKIs are currently a major weapon in the anticancer arsenal. Oral administration, which is convenient for both patients and physicians, and major efficacy in many forms of cancer, explain why these new drugs are currently one of the major options in the fight against cancer. Most medical oncologists are aware of drug-drug interactions with PPIs, (Table 1) but PPIs are frequently prescribed by the primary care physician, and can even be purchased over the counter, resulting in "unknown" drug-drug interactions that can lead to a decrease in efficacy $[34,35]$.

Gefitinib and erlotinib, both selective TKIs targeting the epithelial growth factor receptor, showed reduced absorption in cases of concomitant use with PPIs, [36,37] translating into a significant decrease in efficacy (overall survival and progression-free survival) in retrospective analyses [38,39]. In a large retrospective study of the concomitant use of TKIs and PPIs, nearly 1 in 4 older adults with cancer who received TKIs also received PPIs concomitantly, and this was associated with an increased risk of death-an increase of $21 \%$ in lung cancer patients receiving erlotinib and not associated with discontinued use of TKIs [40]. In this study, no impact was observed in the case of co-prescription of PPIs with sunitinib or imatinib, confirming previous results [41]. However, in a real world study, results on the use of PPIs and the impact on first-line sunitinib treatment outcomes are conflicting [41,42]. No impact on serum concentration with PPI use was demonstrated with osimertinib [43].

In a retrospective analysis of two prospective trials of pazopanib (one single-arm phase 2, EORTC 62043, and one placebo-controlled phase 3 study, EORTC 62072) in softtissue sarcoma patients, of the 333 patients receiving pazopanib, 59 received concomitant PPIs or antiH2; progression-free survival and overall survival were shorter in pazopanib patients receiving gastric antisecretory drugs (respectively 2.8 vs. 4.6 months and 8.0 vs. 12.6 months); these effects were not observed in the placebo group of patients [44].

Clinical pharmacology studies consider that exposure to lenvatinib, vandetanib, cabozantinib, alectinib, and regorafenib is not significantly modified by PPIs [35,45].

Table 1. Pharmacokinetic (PK) interactions between $\mathrm{H} 2$ antagonists (H2A) or proton pump inhibitors (PPI) and tyrosine kinase inhibitors; recommendations and demonstration of the clinical impact of such interactions.

\begin{tabular}{|c|c|c|c|}
\hline Drug Name: & $\begin{array}{c}\text { PK Interactions } \\
{[31,46]}\end{array}$ & $\begin{array}{l}\text { Recommendations } \\
{[31,46]}\end{array}$ & Clinical Impact \\
\hline Afatinib & NA & NA & NA \\
\hline Alectinib & \pm & NA & NA \\
\hline Axitinib & + & H2A: OK, PPI: OK & \\
\hline Cabozantinib & \pm & H2A: OK, PPI: OK & \\
\hline Crizotinib & 0 & H2A: OK, PPI: OK & \\
\hline Dasatinib & ++ & H2A: OK, PPI: no & NA \\
\hline Erlotinib & ++ & H2A: OK, PPI: no & YES [38-40] \\
\hline Gefitinib & +++ & H2A: no, PPI: no & YES [38-40] \\
\hline Imatinib & 0 & H2A: OK, PPI: OK & \\
\hline Lapatinib & + & H2A: no, PPI: no & \\
\hline Lenvatinib & 0 & H2A: OK, PPI: OK & \\
\hline Nilotinib & + & H2A: OK, PPI: OK & \\
\hline Osimertinib & 0 & H2A: OK, PPI: OK & \\
\hline Pazopanib & ++ & H2A: OK, PPI: OK & YES [44] \\
\hline Regorafenib & $0[47]$ & H2A: OK, PPI: OK & \\
\hline Sorafenib & 0 & H2A: OK, PPI: OK & $\begin{array}{c}\text { Conflicting results } \\
{[48-50]}\end{array}$ \\
\hline Sunitinib & + & H2A: OK, PPI: OK & $\begin{array}{c}\text { Conflicting results } \\
{[40-42]}\end{array}$ \\
\hline Vandetanib & + & H2A: OK, PPI: OK & \\
\hline
\end{tabular}

Pharmacokinetic interactions: NA: no data available; 0: definitively no interactions; \pm : conflicting results; +: possible interactions; ++: clear interactions; +++: major interactions. Recommendations: NA: no data available, OK: concomitant use possible; no: concomitant use strongly discouraged. Clinical impact of concomitant use: NA: no data available; YES: clinical impact demonstrated in clinical series; Conflicting results: clinical series showing different results. 
In hepatocellular carcinoma patients, studies have produced contradictory results; a nationwide cohort study from Taiwan compared patients who took TKIs (sorafenib, regorafenib, lenvatinib and cabozantinib) and were PPI users $(n=2196)$ with those who were not PPI users $(n=8013)$. The one-year cumulative incidence of overall mortality was significantly higher in the PPI users $(71.3 \%$ vs. $61.8 \% ; p<0.001)$ and this was confirmed in multiparametric analysis [48]. Similar results were found in a single-centre experience in the UK [49]. However, in secondary analysis of a phase 3 study comparing sorafenib with sunitinib, of the 542 patients receiving sorafenib, 122 were also treated with PPIs at baseline. On univariate and adjusted analyses, no significant association between PPI use and either OS or PFS was identified [50].

\subsection{PPIs and Other Anticancer Treatments}

No known interaction was demonstrated between mTOR inhibitors, PARP inhibitors [51], and PPIs; data regarding BRAF/MEK inhibitors and larotrectinib were scarce but seemed negative [35].

The solubility of palbociclib was reduced at $\mathrm{pH}$ above 4 and coadministration with PPIs decreased both AUC and Cmax [52]. In metastatic breast cancer patients treated with palbociclib, the concomitant use of PPIs may have a detrimental effect on progressionfree survival [53]. On the contrary, gastric $\mathrm{pH}$ did not influence the pharmacokinetics of ribociclib.

No pharmacokinetic interaction between PPIs and oestrogen receptor inhibitors has been described, but enzalutamide, an androgen receptor inhibitor, can decrease the PPIs' plasma levels [54].

\subsection{PPIs and Immunotherapy}

Recent works on preclinical models, confirmed in retrospective analyses, suggest that patients who received antibiotics around the time of the initiation of immune checkpoint inhibitors (ICI) experienced reduced clinical benefits [33,55]. However, in humans, the effects of PPIs are more prominent than the effects of antibiotics on the gut microbiome [21]. Numerous studies have thus addressed the problem of ICI efficacy in PPI users.

In a cohort of 112 melanoma patients treated with anti PD-1, significant differences were observed in the microbiomes of responders versus non-responders [56]. In a retrospective analysis from CheckMate 069, the objective response rate (and PFS) after immunotherapy (ipilimumab alone or combined with nivolumab) in patients receiving PPIs was half that of those not on PPIs [57].

In 2020, retrospective analysis using pooled data from one phase 2 and one phase 3 trial comparing atezolizumab $(n=757)$ with docetaxel $(n=755)$ in previously-treated non-smallcell- lung cancer (the POPLAR and OAK trials) showed that PPI use was associated with shorter OS and PFS in the atezolizumab population and not in the docetaxel population [58]. Individual participant data from two urothelial cancer trials (IMvigor210 and 211) testing the efficacy of atezolizumab were analysed retrospectively with regard to the concomitant use of PPIs (approximately 30\% of patients). In the pooled group of patients receiving atezolizumab ( $\mathrm{n}=847)$, PPI use was a negative prognostic marker (for overall survival, progression-free survival and response rate); in the randomised trial, atezolizumab showed significant efficacy on OS versus chemotherapy (HR: 0.69; 95\% CI: 0.56-0.84) for PPI nonusers and no OS benefit (HR: 1.04; 95\% CI: 0.81-1.34) for PPI users; the same results were observed for PFS and ORR [59]. The phase 3 trial, IMpower 150, compared in non-small cell lung cancers, three chemotherapy regimens, two composed of atezolizumab. In post hoc analysis (1202 participants, 441 receiving PPIs), PPIs use was independently associated with worse overall survival in the pooled atezolizumab arms $(n=748)$, but not in the third arm without ICI [60]. The OS effect of atezolizumab was negative for PPIs users (HR: 1.03; 95\% CI: 0.77-1.36), while it was clearly positive for non-users (HR: 0.68; 95\% CI: 0.54-0.86). The concomitant use of PPIs thus transforms a major breakthrough drug into a treatment that is inefficient. (Table 2) . 
Table 2. Overall survival results of 2 randomised controlled studies comparing atezolizumab vs. systemic chemotherapy with proton pump inhibitor (PPI) users versus non-users. HR: hazard ratio of overall survival of atezolizumab versus chemotherapy.

\begin{tabular}{cccc}
\hline Trial & Subgroup & $\mathbf{n}$ & HR (95\%CI) \\
\hline POPLAR & PPI users & 494 & $0.92(0.75-1.44)$ \\
$\mathrm{n}=1512[58]$ & PPI non-users & 1018 & $0.73(0.62-0.85)$ \\
\hline IMvigor 211 & PPI users & 330 & $1.04(0.81-1.34)$ \\
$\mathrm{N}=$ 931 [59] & PPI non-users & 601 & $0.69(0.56-0.84)$ \\
\hline
\end{tabular}

In a recent Korean cohort study of 2963 patients treated with ICIs as the second line, for non-small cell lung cancer, 936 were concomitant PPIs users. After propensity score matching (1:1 ratio), 1646 were analysed. The use of PPIs was associated with a higher risk of mortality compared to non-use (HR: 1.28; 95\% CI: 1.13-1.46) [61].

An Italian series evaluated the prognostic impact of concomitant treatments (antibiotics, PPIs, or corticosteroids), quantified by a drug score, in a large series of patients receiving pembrolizumab or chemotherapy for non-small cell lung cancer. This drug score had a predictive value for response rate, OS and PFS, essentially in the pembrolizumab cohort [62].

Recently, a meta-analysis of seven studies (3647 cancer patients) was reported. The authors concluded that PPIs' use had a detrimental effect on the efficacy of ICI: PPIs' use increased the risk of death by $39 \%$ and the risk of progression by $28 \%$ [63].

In Bordeaux University Hospital, between May 2015 and September 2017, 635 patients received CPI for cancer. The authors analysed the influence of comedications (including PPIs) on the anti-tumour effect and safety of these CPI. PPIs were prescribed in $38 \%$ of these patients; the median OS of patients receiving PPIs was 9 months versus 26.5 months in those not receiving PPIs (HR: 1.70, 95\%CI: 1.40-2.08) [64].

\subsection{PPIs and Chemotherapeutic Agents}

High doses of parenteral methotrexate are used in some forms of cancer and require strict drug monitoring. In a series of 74 patients receiving high dose methotrexate, it was demonstrated that co-administration of PPIs was associated with delayed elimination of methotrexate, as well as renal and liver dysfunction [65]. The mechanism is uncertain, but PPIs should be used cautiously with a high dose of methotrexate.

In 2017, secondary unplanned analysis of the TRIO-013 trial comparing capecitabine and oxaliplatin (CapOx) with or without lapatinib in ERB2-positive metastatic gastroesophageal cancer aimed to determine if orally administered capecitabine or lapatinib were hampered by concomitant prescription of PPIs [66]. Of the 545 randomised patients, $229(42 \%)$ evenly distributed patients received PPIs. In the placebo arm (receiving CapOx only), patients treated with PPIs had worse efficacy results (PFS, disease control rate, and OS) than those not receiving PPIs. The same authors conducted retrospective analysis of patients with stage II-III colorectal cancer who received adjuvant CapOx or FOLFOX in Edmonton, Alberta. Between 2004 and 2013, 389 patients, 214 receiving CapeOx and 175 receiving FOLFOX, met their inclusion criteria; respectively, 50 (23.4\%) and 49 (28\%) had concomitant PPIs. Three-year recurrence-free survival was significantly lower in the CapeOx-treated PPIs recipients than the non-PPIs recipients. This was not demonstrated in the FOLFOX-treated PPI recipients, but the differences were minor [67]. More recently, secondary analysis of six randomised controlled trials in patients with advanced colorectal cancer treated with fluoropyrimidines was conducted using individual patient data. Of the 5594 patients included, 902 received PPIs at trial entry. PPIs' use was significantly associated with worse overall survival (pooled HR, 1.20; 95\% CI, 1.03-1.40; $p=0.02$ ) and progression-free survival (overall pooled HR, $1.20 ; 965 \%$ CI: 1.05-1.37; $p=0.009$ ); this was particularly obvious for patients under 5FU and not among those receiving capecitabine; nor was it obvious for patients treated with other gastric antisecretory drugs (such as $\mathrm{H} 2$ 
antagonists). The authors concluded that clinicians should cautiously consider the concomitant use of PPIs in such patients. The mechanistic basis was unclear: impact on several transporters, modifications to intracellular $\mathrm{pH}$, or something else [68]. Future studies are thus warranted as a series are accumulating on such possible interactions [69].

\section{Conclusions}

To conclude, the effect of PPIs on the efficacy of certain anticancer agents, particularly TKIs and CPIs, is a major issue in daily practice. In this opinion paper, we have put emphasis on articles showing the potential negative impact of such combinations and particularly on unplanned retrospective analysis from prospective studies, because we can expect that no randomized trial can be and will be conducted on this topic; moreover, PPIs are symptomatic treatments that can be replaced without any major risk of interactions. There are articles that did not find clinical interactions, particularly with CPIs [70-72], but we think that the precautionary principle must be applied until there is demonstration of the absence of clinical interaction. It is certainly of major importance that patients can be helped to stop taking PPIs after four weeks of treatment, except in cases of severe oesophagitis, previous bleeding, or Barrett's oesophagus, [73] and ideally that prescriptions of PPIs be avoided for heartburn or epigastralgia. Some tricks, such as drinking acidic beverages (cola) with erlotinib could be proposed, but the best way is certainly to replace these long-lasting drugs with other therapeutic means [74]. If the use of acid-suppressive drugs is necessary, $\mathrm{H} 2$ antagonists (ranitidine) can be used and given $2 \mathrm{~h}$ after TKIs. Antacids can also be used $2 \mathrm{~h}$ before or after the drug [31]. The use of PPIs should be limited to TKIs with no proven interactions between absorption and intragastric $\mathrm{pH}$. In patients treated with CPIs, the interaction is not due to drug absorption but rather to the alteration of the gut microbiome and we can suppose that the negative effect may also be observed after long-term use of $\mathrm{H} 2$ antagonists. In such cases, antacids are the best option, although on-demand use of PPIs or H2 antagonists may also be proposed.

Author Contributions: Conceptualization, J.-L.R. and J.-S.F.; validation, all authors.; writingoriginal draft preparation, J.-L.R.; writing-review and editing, J.-L.R., J.E., M.G.; visualization, all authors.; supervision, V.S., C.M.-B. All authors have read and agreed to the published version of the manuscript.

Funding: The APC was funded by Institut de Cancérologie de l'Ouest.

Conflicts of Interest: The authors declare no conflict of interest.

\section{References}

1. Vaezi, M.F.; Yang, Y.X.; Howden, C.W. Complications of Proton Pump Inhibitor Therapy. Gastroenterology $2017,153,35-48$. [CrossRef] [PubMed]

2. Forgacs, I.; Loganayagam, A. Overprescribing proton pump inhibitors. BMJ 2008, 336, 2-3. [CrossRef] [PubMed]

3. Lodato, F.; Poluzzi, E.; Raschi, E.; Piccinni, C.; Koci, A.; Olivelli, V.; Napoli, C.; Corvalli, G.; Nalon, E.; De Ponti, F.; et al. Appropriateness of Proton Pump Inhibitor (PPI) prescription in patients admitted to hospital: Attitudes of general practitioners and hospital physicians in Italy. Eur. J. Intern. Med. 2016, 30, 31-36. [CrossRef]

4. Ekman, L.; Hansson, E.; Havu, N.; Carlsson, E.; Lundberg, C. Toxicological studies on omeprazole. Scand. J. Gastroenterol. Suppl. 1985, 108, 53-69. [PubMed]

5. Savarino, V.; Marabotto, E.; Furnari, M.; Zingone, F.; Zentilin, P.; Savarino, E. Latest insights into the hot question of proton pump inhibitor safety-A narrative review. Dig. Liver Dis. 2020, 52, 842-852. [CrossRef]

6. Raoul, J.L.; Guerin-Charbonnel, C.; Edeline, J.; Simmet, V.; Gilabert, M.; Frenel, J.S. Prevalence of Proton Pump Inhibitor Use Among Patients With Cancer. JAMA Netw. Open 2021, 4, e2113739. [CrossRef]

7. Weersma, R.K.; Zhernakova, A.; Fu, J. Interaction between drugs and the gut microbiome. Gut 2020, 69, 1510-1519. [CrossRef]

8. Tvingsholm, S.A.; Dehlendorff, C.; Osterlind, K.; Friis, S.; Jaattela, M. Proton pump inhibitor use and cancer mortality. Int. J. Cancer 2018, 143, 1315-1326. [CrossRef]

9. Wang, X.; Liu, Q.; Halfdanarson, O.O.; Zoega, H.; Sadr-Azodi, O.; Engstrand, L.; Fall, K.; Brusselaers, N. Proton pump inhibitors and survival in patients with colorectal cancer: A Swedish population-based cohort study. Br. J. Cancer 2021, 125, 893-900. [CrossRef] 
10. Raoul, J.L.; Edeline, J.; Gilabert, M.; Senellart, H.; Frenel, J.S. Proton pump inhibitors and cancers: A hazardous association? Bull. Cancer 2020, 107, 458-464. [CrossRef]

11. Badiola, N.; Alcalde, V.; Pujol, A.; Munter, L.M.; Multhaup, G.; Lleo, A.; Coma, M.; Soler-Lopez, M.; Aloy, P. The proton-pump inhibitor lansoprazole enhances amyloid beta production. PLoS ONE 2013, 8, e58837.

12. Gomm, W.; von Holt, K.; Thome, F.; Broich, K.; Maier, W.; Fink, A.; Doblhammer, G.; Haenisch, B. Association of Proton Pump Inhibitors with Risk of Dementia: A Pharmacoepidemiological Claims Data Analysis. JAMA Neurol. 2016, 73, 410-416. [CrossRef] [PubMed]

13. Hill, A.B. The Environment and Disease: Association or Causation? Proc. R. Soc. Med. 1965, 58, 295-300. [CrossRef] [PubMed]

14. van der Hoorn, M.M.C.; Tett, S.E.; de Vries, O.J.; Dobson, A.J.; Peeters, G. The effect of dose and type of proton pump inhibitor use on risk of fractures and osteoporosis treatment in older Australian women: A prospective cohort study. Bone 2015, 81, 675-682. [CrossRef]

15. Freedberg, D.E.; Kim, L.S.; Yang, Y.X. The Risks and Benefits of Long-term Use of Proton Pump Inhibitors: Expert Review and Best Practice Advice From the American Gastroenterological Association. Gastroenterology 2017, 152, 706-715. [CrossRef]

16. Andersen, B.N.; Johansen, P.B.; Abrahamsen, B. Proton pump inhibitors and osteoporosis. Curr. Opin. Rheumatol. 2016, 28, 420-425. [CrossRef]

17. Coleman, R.; Body, J.J.; Aapro, M.; Hadji, P.; Herrstedt, J.; Group, E.G.W. Bone health in cancer patients: ESMO Clinical Practice Guidelines. Ann. Oncol. 2014, 25 (Suppl. S3), iii124-iii137. [CrossRef]

18. Lazarus, B.; Chen, Y.; Wilson, F.P.; Sang, Y.; Chang, A.R.; Coresh, J.; Grams, M.E. Proton Pump Inhibitor Use and the Risk of Chronic Kidney Disease. JAMA Intern. Med. 2016, 176, 238-246. [CrossRef]

19. Giusti, S.; Lin, Y.; Sogbetun, F.; Nakhoul, N.; Liu, S.; Shi, L.; Batuman, V. The Effect of Proton Pump Inhibitor Use on the Course of Kidney Function in Patients with Chronic Kidney Disease Stages G3a to G4. Am. J. Med. Sci. 2021, 362, 453-461. [CrossRef]

20. Hall, R.K.; Blumenthal, J.B.; Doerfler, R.M.; Chen, J.; Diamantidis, C.J.; Jaar, B.G.; Kusek, J.W.; Kallem, K.; Leonard, M.B.; Navaneethan, S.D.; et al. Risk of Potentially Inappropriate Medications in Adults with CKD: Findings from the Chronic Renal Insufficiency Cohort (CRIC) Study. Am. J. Kidney Dis. 2021, 78, 837-845. [CrossRef]

21. Imhann, F.; Bonder, M.J.; Vich Vila, A.; Fu, J.; Mujagic, Z.; Vork, L.; Tigchelaar, E.F.; Jankipersading, S.A.; Cenit, M.C.; Harmsen, H.J.; et al. Proton pump inhibitors affect the gut microbiome. Gut 2016, 65, 740-748. [CrossRef] [PubMed]

22. Laheij, R.J.; Sturkenboom, M.C.; Hassing, R.J.; Dieleman, J.; Stricker, B.H.; Jansen, J.B. Risk of community-acquired pneumonia and use of gastric acid-suppressive drugs. JAMA 2004, 292, 1955-1960. [CrossRef] [PubMed]

23. Jensen, R.T. Consequences of long-term proton pump blockade: Insights from studies of patients with gastrinomas. Basic Clin. Pharmacol. Toxicol. 2006, 98, 4-19. [CrossRef] [PubMed]

24. Stewart, C.A.; Termanini, B.; Sutliff, V.E.; Serrano, J.; Yu, F.; Gibril, F.; Jensen, R.T. Iron absorption in patients with Zollinger-Ellison syndrome treated with long-term gastric acid antisecretory therapy. Aliment. Pharmacol. Ther. 1998, 12, 83-98. [CrossRef]

25. Vanclooster, A.; van Deursen, C.; Jaspers, R.; Cassiman, D.; Koek, G. Proton Pump Inhibitors Decrease Phlebotomy Need in HFE Hemochromatosis: Double-Blind Randomized Placebo-Controlled Trial. Gastroenterology 2017, 153, 678-680.e2. [CrossRef] [PubMed]

26. Ajmera, A.V.; Shastri, G.S.; Gajera, M.J.; Judge, T.A. Suboptimal response to ferrous sulfate in iron-deficient patients taking omeprazole. Am. J. Ther. 2012, 19, 185-189. [CrossRef] [PubMed]

27. Cheungpasitporn, W.; Thongprayoon, C.; Kittanamongkolchai, W.; Srivali, N.; Edmonds, P.J.; Ungprasert, P.; O'Corragain, O.A.; Korpaisarn, S.B.; Erickson, S. Proton pump inhibitors linked to hypomagnesemia: A systematic review and meta-analysis of observational studies. Ren. Fail. 2015, 37, 1237-1241. [CrossRef]

28. Recart, D.A.; Ferraris, A.; Petriglieri, C.I.; Alonso Serena, M.; Bonella, M.B.; Posadas-Martinez, M.L. Prevalence and risk factors of long-term proton pump inhibitors-associated hypomagnesemia: A cross-sectional study in hospitalized patients. Intern. Emerg. Med. 2021, 16, 711-717. [CrossRef]

29. van Leeuwen, R.W.F.; Jansman, F.G.A.; Hunfeld, N.G.; Peric, R.; Reyners, A.K.L.; Imholz, A.L.T.; Brouwers, J.; Aerts, J.G.; van Gelder, T.; Mathijssen, R.H.J. Tyrosine Kinase Inhibitors and Proton Pump Inhibitors: An Evaluation of Treatment Options. Clin. Pharmacokinet. 2017, 56, 683-688. [CrossRef]

30. Budha, N.R.; Frymoyer, A.; Smelick, G.S.; Jin, J.Y.; Yago, M.R.; Dresser, M.J.; Holden, S.N.; Benet, L.Z.; Ware, J.A. Drug absorption interactions between oral targeted anticancer agents and PPIs: Is pH-dependent solubility the Achilles heel of targeted therapy? Clin. Pharmacol. Ther. 2012, 92, 203-213. [CrossRef]

31. van Leeuwen, R.W.; van Gelder, T.; Mathijssen, R.H.; Jansman, F.G. Drug-drug interactions with tyrosine-kinase inhibitors: A clinical perspective. Lancet Oncol. 2014, 15, e315-e326. [CrossRef]

32. Indini, A.; Petrelli, F.; Tomasello, G.; Rijavec, E.; Facciorusso, A.; Grossi, F.; Ghidini, M. Impact of Use of Gastric-Acid Suppressants and Oral Anti-Cancer Agents on Survival Outcomes: A Systematic Review and Meta-Analysis. Cancers 2020, 12, 998. [CrossRef] [PubMed]

33. Routy, B.; Le Chatelier, E.; Derosa, L.; Duong, C.P.M.; Alou, M.T.; Daillere, R.; Fluckiger, A.; Messaoudene, M.; Raubert, C.; Roberti, M.P.; et al. Gut microbiome influences efficacy of PD-1-based immunotherapy against epithelial tumors. Science 2018, 359, 91-97. [CrossRef] [PubMed]

34. Parsad, S.; Ratain, M.J. Drug-Drug Interactions With Oral Antineoplastic Agents. JAMA Oncol. 2017, 3, 736-738. [CrossRef] 
35. Uchiyama, A.A.T.; Silva, P.; Lopes, M.S.M.; Yen, C.T.; Ricardo, E.D.; Mutao, T.; Pimenta, J.R.; Machado, L.M.; Shimba, D.S.; Peixoto, R.D. Proton Pump Inhibitors and Oncologic Treatment Efficacy: A Practical Review of the Literature for Oncologists. Curr. Oncol. 2021, 28, 783-799. [CrossRef]

36. Peters, S.; Zimmermann, S.; Adjei, A.A. Oral epidermal growth factor receptor tyrosine kinase inhibitors for the treatment of non-small cell lung cancer: Comparative pharmacokinetics and drug-drug interactions. Cancer Treat. Rev. 2014, 40, 917-926. [CrossRef]

37. Veerman, G.D.M.; Hussaarts, K.; Peric, R.; Oomen-de Hoop, E.; Landa, K.D.; van der Leest, C.H.; Broerse, S.D. Influence of Cow's Milk and Esomeprazole on the Absorption of Erlotinib: A Randomized, Crossover Pharmacokinetic Study in Lung Cancer Patients. Clin. Pharmacokinet. 2021, 60, 69-77. [CrossRef]

38. Chu, M.P.; Ghosh, S.; Chambers, C.R.; Basappa, N.; Butts, C.A.; Chu, Q.; Fenton, D.; Joy, A.A.; Sangha, R.; Smylie, M.; et al. Gastric Acid suppression is associated with decreased erlotinib efficacy in non-small-cell lung cancer. Clin. Lung Cancer 2015, 16, 33-39. [CrossRef]

39. Fang, Y.H.; Yang, Y.H.; Hsieh, M.J.; Hung, M.S.; Lin, Y.C. Concurrent proton-pump inhibitors increase risk of death for lung cancer patients receiving 1st-line gefitinib treatment-A nationwide population-based study. Cancer Manag. Res. 2019, 11, 8539-8546. [CrossRef]

40. Sharma, M.; Holmes, H.M.; Mehta, H.B.; Chen, H.; Aparasu, R.R.; Shih, Y.T.; Giordano, S.H.; Johnson, M.L. The concomitant use of tyrosine kinase inhibitors and proton pump inhibitors: Prevalence, predictors, and impact on survival and discontinuation of therapy in older adults with cancer. Cancer 2019, 125, 1155-1162. [CrossRef]

41. Lalani, A.A.; McKay, R.R.; Lin, X.; Simantov, R.; Kaymakcalan, M.D.; Choueiri, T.K. Proton Pump Inhibitors and Survival Outcomes in Patients With Metastatic Renal Cell Carcinoma. Clin. Genitourin. Cancer 2017, 15, 724-732. [CrossRef] [PubMed]

42. Boegemann, M.; Schlack, K.; Rink, M.; Bernhardt, S.; Moran, M.; Hubbe, M.; Bergmann, L.; Schmid, M.; Strauss, A. Effect of comorbidities/comedications on sunitinib outcomes for metastatic renal cell carcinoma: The STAR-TOR registry. Future Oncol. 2020, 16, 2939-2948. [CrossRef]

43. Vishwanathan, K.; Dickinson, P.A.; Bui, K.; Cassier, P.A.; Greystoke, A.; Lisbon, E.; Moreno, V.; So, K.; Thomas, K.; Weilert, D.; et al. The Effect of Food or Omeprazole on the Pharmacokinetics of Osimertinib in Patients with Non-Small-Cell Lung Cancer and in Healthy Volunteers. J. Clin. Pharmacol. 2018, 58, 474-484. [CrossRef] [PubMed]

44. Mir, O.; Touati, N.; Lia, M.; Litiere, S.; Le Cesne, A.; Sleijfer, S.; Blay, J.Y.; Leahy, M.; Young, R.; Mathijssen, R.H.J.; et al. Impact of Concomitant Administration of Gastric Acid-Suppressive Agents and Pazopanib on Outcomes in Soft-Tissue Sarcoma Patients Treated within the EORTC 62043/62072 Trials. Clin. Cancer Res. 2019, 25, 1479-1485. [CrossRef] [PubMed]

45. de Man, F.M.; Hussaarts, K.; de With, M.; Oomen-de Hoop, E.; de Bruijn, P.; van Halteren, H.K.; van der Burg-de Graauw, N.; Eskens, F.; van Gelder, T.; van Leeuwen, R.W.F.; et al. Influence of the Proton Pump Inhibitor Esomeprazole on the Bioavailability of Regorafenib: A Randomized Crossover Pharmacokinetic Study. Clin. Pharmacol. Ther. 2019, 105, 1456-1461. [CrossRef] [PubMed]

46. Hussaarts, K.; Veerman, G.D.M.; Jansman, F.G.A.; van Gelder, T.; Mathijssen, R.H.J.; van Leeuwen, R.W.F. Clinically relevant drug interactions with multikinase inhibitors: A review. Ther Adv. Med. Oncol. 2019, 11, 1758835918818347. [CrossRef]

47. Bezabeh, S.; Mackey, A.C.; Kluetz, P.; Jappar, D.; Korvick, J. Accumulating evidence for a drug-drug interaction between methotrexate and proton pump inhibitors. Oncologist 2012, 17, 550-554. [CrossRef]

48. Wu, C.Y.; Ho, H.J.; Wu, C.Y.; Chen, Y.J.; Lee, T.Y.; Hsu, Y.C.; Lin, J.T. Association between proton pump inhibitor use and mortality in patients with hepatocellular carcinoma receiving tyrosine kinase inhibitor. Gut 2020, 70, 1598-1599. [CrossRef]

49. Razak, R.A.; Fletcher, P.; Kunene, V.; Ma, Y.T. Association of Gastric Acid Suppression and Sorafenib Efficacy in Advanced Hepatocellular Carcinoma. J. Clin. Gastroenterol. 2020, 55, 169-173. [CrossRef]

50. Ruanglertboon, W.; Sorich, M.J.; Logan, J.M.; Rowland, A.; Hopkins, A.M. The effect of proton pump inhibitors on survival outcomes in advanced hepatocellular carcinoma treated with sorafenib. J. Cancer Res. Clin. Oncol. 2020, 146, 2693-2697. [CrossRef]

51. Li, L.; Xiang, Y.X.; Yang, G.P.; Zhang, X.F.; Yang, X.Y.; Yang, S.; Huang, J. Pharmacokinetic effects of proton pump inhibitors on the novel PARP inhibitor fluzoparib: A single-arm, fixed-sequence trial in male healthy volunteers. Investig. New Drugs 2021, 39, 796-802. [CrossRef] [PubMed]

52. Sun, W.; Klamerus, K.J.; Yuhas, L.M.; Pawlak, S.; Plotka, A.; O’Gorman, M.; Kirkovsky, L.; Kosa, M.; Wang, D. Impact of Acid-Reducing Agents on the Pharmacokinetics of Palbociclib, a Weak Base With pH-Dependent Solubility, With Different Food Intake Conditions. Clin. Pharmacol. Drug Dev. 2017, 6, 614-626. [CrossRef] [PubMed]

53. Del Re, M.; Omarini, C.; Diodati, L.; Palleschi, M.; Meattini, I.; Crucitta, S.; Lorenzini, G.; Isca, C.; Fontana, A.; Livi, L.; et al. Drug-drug interactions between palbociclib and proton pump inhibitors may significantly affect clinical outcome of metastatic breast cancer patients. ESMO Open. 2021, 6, 100231. [CrossRef]

54. Gibbons, J.A.; de Vries, M.; Krauwinkel, W.; Ohtsu, Y.; Noukens, J.; van der Walt, J.S.; Mol, R.; Mordenti, J.; Ouatas, T. Pharmacokinetic Drug Interaction Studies with Enzalutamide. Clin. Pharmacokinet. 2015, 54, 1057-1069. [CrossRef]

55. Derosa, L.; Hellmann, M.D.; Spaziano, M.; Halpenny, D.; Fidelle, M.; Rizvi, H.; Long, N.; Plodkowski, A.J.; Arbour, K.C.; Chaft, J.E.; et al. Negative association of antibiotics on clinical activity of immune checkpoint inhibitors in patients with advanced renal cell and non-small-cell lung cancer. Ann. Oncol. 2018, 29, 1437-1444. [CrossRef] 
56. Gopalakrishnan, V.; Spencer, C.N.; Nezi, L.; Reuben, A.; Andrews, M.C.; Karpinets, T.V.; Prieto, P.A.; Vincente, D.; Hoffman, K.; Wei, S.C.; et al. Gut microbiome modulates response to anti-PD-1 immunotherapy in melanoma patients. Science 2018, 359, 97-103. [CrossRef]

57. Homicsko, K.; Richtig, G.; Tuchmann, F.; Tsourti, Z.; Hanahan, D.; Coukos, G.; Wind-Rotolo, M.; Richtig, E.; Zygoura, P.; Holler, C.; et al. Proton pump inhibitors negatively impact survival of PD-1 inhibitor based therapies in metastatic melanoma patients. Ann. Oncol. 2018, 29, x40. [CrossRef]

58. Chalabi, M.; Cardona, A.; Nagarkar, D.R.; Dhawahir Scala, A.; Gandara, D.R.; Rittmeyer, A.; Albert, M.L.; Powles, T.; Kok, M.; Herrera, F.G.; et al. Efficacy of chemotherapy and atezolizumab in patients with non-small-cell lung cancer receiving antibiotics and proton pump inhibitors: Pooled post hoc analyses of the OAK and POPLAR trials. Ann. Oncol. 2020, 31, 525-531. [CrossRef]

59. Hopkins, A.M.; Kichenadasse, G.; Karapetis, C.S.; Rowland, A.; Sorich, M.J. Concomitant Proton Pump Inhibitor Use and Survival in Urothelial Carcinoma Treated with Atezolizumab. Clin. Cancer Res. 2020, 26, 5487-5493. [CrossRef]

60. Hopkins, A.M.; Kichenadasse, G.; McKinnon, R.A.; Abuhelwa, A.Y.; Logan, J.M.; Badaoui, S.; Karapetis, C.S.; Rowland, A.; Sorich, M.J. Efficacy of first-line atezolizumab combination therapy in patients with non-small cell lung cancer receiving proton pump inhibitors: Post hoc analysis of IMpower150. Br. J. Cancer 2022, 126, 42-47. [CrossRef]

61. Baek, Y.H.; Kang, E.J.; Hong, S.; Park, S.H.; Kim, J.H.; Shin, J.Y. Survival outcomes of patients with non-small cell lung cancer concomitantly receiving proton pump inhibitors and immune checkpoint inhibitors. Int. J. Cancer 2022, 150, 1291-1300. [CrossRef] [PubMed]

62. Buti, S.; Bersanelli, M.; Perrone, F.; Bracarda, S.; Di Maio, M.; Giusti, R.; Nigro, O.; Cortinovis, D.L.; Aerts, J.; Guaitoli, G.; et al. Predictive ability of a drug-based score in patients with advanced non-small-cell lung cancer receiving first-line immunotherapy. Eur. J. Cancer 2021, 150, 224-231. [CrossRef] [PubMed]

63. Qin, B.D.; Jiao, X.D.; Zhou, X.C.; Shi, B.; Wang, J.; Liu, K.; Wu, Y.; Ling, Y.; Zang, Y.S. Effects of concomitant proton pump inhibitor use on immune checkpoint inhibitor efficacy among patients with advanced cancer. Oncoimmunology 2021, 10, 1929727. [CrossRef] [PubMed]

64. Kostine, M.; Mauric, E.; Tison, A.; Barnetche, T.; Barre, A.; Nikolski, M.; Rouxel, L.; Dutriaux, C.; Dousset, L.; Prey, S.; et al. Baseline co-medications may alter the anti-tumoural effect of checkpoint inhibitors as well as the risk of immune-related adverse events. Eur. J. Cancer 2021, 157, 474-484. [CrossRef]

65. Suzuki, K.; Doki, K.; Homma, M.; Tamaki, H.; Hori, S.; Ohtani, H.; Sawada, Y.; Kohda, Y. Co-administration of proton pump inhibitors delays elimination of plasma methotrexate in high-dose methotrexate therapy. Br. J. Clin. Pharmacol. 2009, 67, 44-49. [CrossRef]

66. Chu, M.P.; Hecht, J.R.; Slamon, D.; Wainberg, Z.A.; Bang, Y.J.; Hoff, P.M.; Sobrero, A.; Qin, S.; Afenjar, K.; Houe, V.; et al. Association of Proton Pump Inhibitors and Capecitabine Efficacy in Advanced Gastroesophageal Cancer: Secondary Analysis of the TRIO-013/LOGiC Randomized Clinical Trial. JAMA Oncol. 2017, 3, 767-773. [CrossRef]

67. Wong, G.G.; Ha, V.; Chu, M.P.; Dersch-Mills, D.; Ghosh, S.; Chambers, C.R.; Sawyer, M.B. Effects of Proton Pump Inhibitors on FOLFOX and CapeOx Regimens in Colorectal Cancer. Clin. Colorectal Cancer. 2019, 18, 72-79. [CrossRef]

68. Kichenadasse, G.; Miners, J.O.; Mangoni, A.A.; Karapetis, C.S.; Hopkins, A.M.; Sorich, M.J. Proton Pump Inhibitors and Survival in Patients With Colorectal Cancer Receiving Fluoropyrimidine-Based Chemotherapy. J. Natl. Compr. Cancer Netw. 2021, 19, 1037-1044. [CrossRef]

69. Pouya, F.D.; Rasmi, Y.; Camci, I.Y.; Tutar, Y.; Nemati, M. Performance of capecitabine in novel combination therapies in colorectal cancer. J. Chemother. 2021, 33, 375-389. [CrossRef]

70. Peng, K.; Chen, K.; Teply, B.A.; Yee, G.C.; Farazi, P.A.; Lyden, E.R. Impact of Proton Pump Inhibitor Use on the Effectiveness of Immune Checkpoint Inhibitors in Advanced Cancer Patients. Ann. Pharmacother. 2021, 10600280211033938. [CrossRef]

71. Li, C.; Xia, Z.; Li, A.; Meng, J. The effect of proton pump inhibitor uses on outcomes for cancer patients treated with immune checkpoint inhibitors: A meta-analysis. Ann. Transl. Med. 2020, 8, 1655. [CrossRef] [PubMed]

72. Mollica, V.; Santoni, M.; Matrana, M.R.; Basso, U.; De Giorgi, U.; Rizzo, A.; Maruzzo, M.; Marchetti, A.; Rosellini, M.; Bleve, S.; et al. Concomitant Proton Pump Inhibitors and Outcome of Patients Treated with Nivolumab Alone or Plus Ipilimumab for Advanced Renal Cell Carcinoma. Target. Oncol. 2022, 17, 61-68. [CrossRef] [PubMed]

73. Farrell, B.; Pottie, K.; Thompson, W.; Boghossian, T.; Pizzola, L.; Rashid, F.J.; Rojas-Fernandez, C.; Walsh, K.; Welch, V.; Moayyedi, P. Deprescribing proton pump inhibitors: Evidence-based clinical practice guideline. Can. Fam. Physician 2017, 63, 354-364.

74. van Leeuwen, R.W.; Peric, R.; Hussaarts, K.G.; Kienhuis, E.; IJzerman, N.S.; de Bruijn, P.; van der Leest, C.; Codrington, H.; Kloovert, J.S.; van der Holt, B.; et al. Influence of the Acidic Beverage Cola on the Absorption of Erlotinib in Patients with Non-Small-Cell Lung Cancer. J. Clin. Oncol. 2016, 34, 1309-1314. [CrossRef] 